\title{
ResearchArticle
}

\section{Genetic divergence analysis in bread wheat (Triticum aestivum L.)}

\author{
MANISHA SAINI, SHWETA AND SUNIL KUMAR PASWAN
}

\begin{abstract}
SUMMARY
Fifty genotype of wheat were evaluated to access the genetic divergence for eleven quantitative traits. The $\mathrm{D}^{2}$ cluster analysis grouped 50 genotypes in to eight clusters. This indicates existence of high degree of genetic diversity in the genotypes evaluated. Analysis of variance show significant difference among all the genotype under study. Maximum inter-cluster distance was observed between cluster VII with all. Cluster VIII holds first rank in yield per plant, test weight and plant height, cluster VII holds first rank in plant height, number of reproductive tillers per plant, number of spikelet per spike. Therefore, crosses between member of cluster separated by high inter-cluster distance are likely to throw desirable segregants. Thus, crosses between promising lines belonging to clusters pairs having high inter-cluster distance may be attempted for isolating desirable recombinants for grain yield.
\end{abstract}

Key Words : Cluster, $D^{2}$ analysis, Genetic variation, Inter cluster distance, Transgressive segregants

How to cite this article : Saini, .Manisha, Shweta and Paswan, Sunil Kumar (2017). Genetic divergence analysis in bread wheat (Triticum aestivum L.). Internat. J. Plant Sci., 12 (2): 249-252, DOI: 10.15740/HAS/IJPS/12.2/249-252.

Article chronicle : Received : 16.02.2017; Revised : 03.06.2017; Accepted : 19.06.2017

\section{MEMBERS OF THE RESEARCH FORUM}

